\title{
Entrevista: \\ Escola Secundária de Estarreja
}

Por sair um pouco da linha das entrevistas anteriores, esta necessita de uma nota prévia. De facto, a história desta entrevista começa bem longe da Escola Secundária de Estarreja e dos seus alunos e professores. Começa com um comentário de uma colega minha: "Os senhores da SPQ é que deviam visitar esta exposição organizada pela Escola Secundária X, para verem o que de bom se faz no secundário!". Como faço parte da direcção da SPQ, calculei que também fosse um "senhor da SPQ" e perguntei: "E avisaram alguém da SPQ acerca desta iniciativa?". "Não... mas estou a avisá-lo agora a si...". "E a exposição dura até quando?". "Acabou hoje..."

Há, de facto, muitas actividades meritórias que a SPQ deveria conhecer e ajudar a divulgar, muitas até que teria a obrigação de apoiar dentro das suas possibilidades (oferta de prémios, participação de conferencistas, divul- gação aos sócios da região, etc.). Mas, para que tudo isso suceda, alguém tem de fazer chegar a informação aos membros da direcção! Já agora: os contactos dos membros da direcção da SPQ - que inclui os presidentes das Delegações Regionais - estão acessiveis em www.spq.pt.

Foi pouco depois do episódio acima descrito que surgiu a oportunidade desta entrevista: a Escola Secundária de Estarreja apareceu na Universidade de Aveiro para apresentar o seu espectáculo "A Magia da Ciência", a convite da Dra. Clara Magalhães (presidente da Delegação Regional de Aveiro). Uma excelente ocasião para uma entrevista diferente, com professores e alunos, efectuada entre duas representações de um espectáculo muito participado.

Os professores entrevistados: Lúcia Salgado, Juvelina Centeno Amaro e António Almeida.
PRC - Vou começar pela professora Juvelina, que eu conheço como participante activa das Olimpíadas de Química... diga-nos, o que é que se passou aqui hoje?

JCA - Foi um espectáculo de magia - "A Magia da Ciência". Primeiro tentámos mostrar alguns fenómenos de uma forma mágica, para posteriormente isso ser desmistificado e explicarmos tudo o que se passou à luz da ciência. Ou seja, começámos com uma fase de espectáculo, seguida de outra fase com a explicação científica de tudo o que se passou.

PRC- Como é que este projecto surgiu na Escola? Ou melhor, como é que um grupo de professores e alunos - em vez de estarem numa sala de aula - se envolvem num espectáculo com vassouras e chapéus de bico?

JCA - Este espectáculo está integrado num projecto que se realiza todos os anos - desde há algum tempo - designado "Encontros com a Ciência" e que envolve o Departamento de Ciências Experimentais da Escola, ou seja, os professores (e alunos, obviamente) de Química, Física, Biologia e Geologia.

PRC - Trata-se, portanto, de um projecto multidisciplinar...

JCA - Sim. E há muitos professores envolvidos... Há um tema central, que é depois dividido em sub-temas a serem abordados nos diferentes laboratórios (química, física, biologia, geologia), mas todos tratados de forma multidisciplinar. A nós coube-nos tratar da "Magia da Ciência"...

PRC - Vou sublinhar aqui o facto de ser um projecto multidisciplinar e aproveitar para incluir também nesta conversa a professora Lúcia Salgado, delegada de grupo de Química. É fácil conseguir manter essa multidisciplinaridade?
LS - É complicado. O nosso Departamento tem os professores distribuídos por quatro grupos: Química, Física, Biologia e Geologia. Há sempre visões diferentes, por vezes há conflitos de opinião ou de projectos... mas a discussão também é positiva, e geralmente no final com grande ajuda dos alunos - tudo acaba por bem.

JCA - Mas fácil não é... é possível, devido à boa vontade de todos os professores envolvidos. Por exemplo, nós não temos horários compatíveis e, portanto, temos de nos encontrar fora do horáric normal para coordenar as actividades.

PRC - Falemos então um pouco dos "Encontros com a Ciência"... como é que surgiram? A que público se destinam?

JCA - Inicialmente era uma semana de divulgação da ciência, designada Semana da Ciência, dirigida aos alunos do $9 .^{\circ}$ ano. Depois foi-se alargando à comuni- 


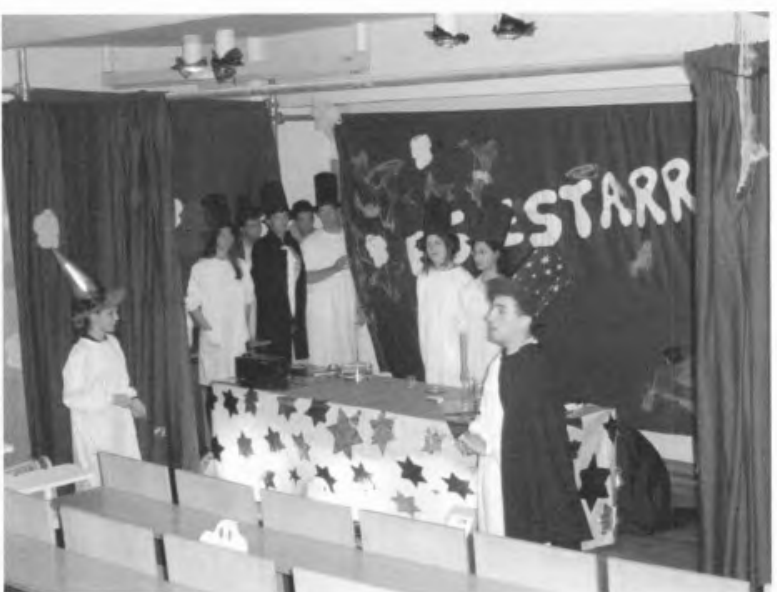

figura $1 \mathrm{I}$ acto

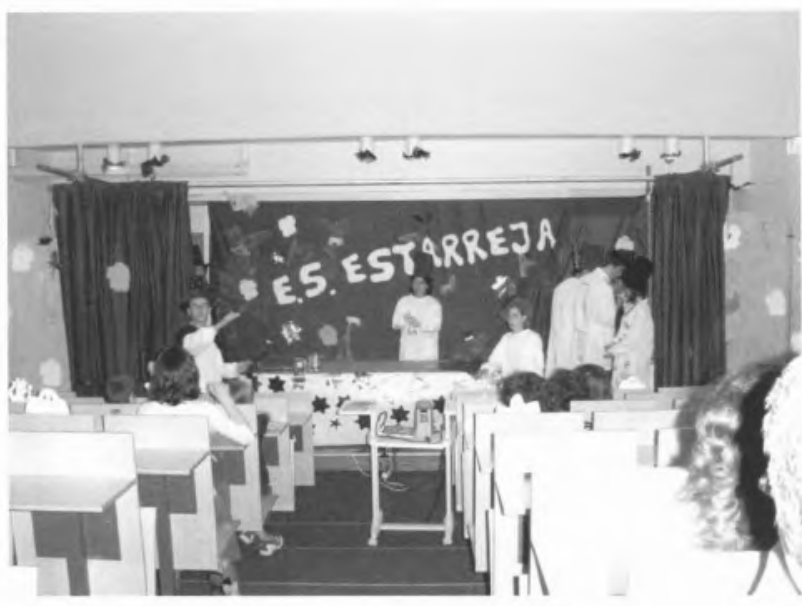

figura 2 II acto dade. Já tivemos visitas de alunos de escolas primárias, pré-primárias... Actualmente, os "Encontros com a Ciência" duram 3 dias, com actividades de manhã, à tarde e à noite...

\section{PRC- À noite?}

JCA - ... para dar aos encarregados de educação oportunidade de virem à escola, ver as actividades.

LS - Mas essa questão (o público a que se destina), está actualmente em discussão. Realmente, tudo começou dirigido aos alunos do $9 .^{\circ}$ ano... para os ajudar a escolher a carreira no secundário, já que viriam para o $10{ }^{\circ}$ ano no ano seguinte. Este ano houve, de facto, visitas de alunos da primária, mas não resultou muito bem. Havia muitas experiências que eles não podiam compreender... e também foi criado o horário da noite, para os pais, e houve convites aos industriais da região... mas ainda estamos a avaliar estas opções, para escolher o modelo a seguir.

PRC - Esta iniciativa da Semana da Ciência encontra facilmente apoio da direcção da Escola?

LS - Evidentemente, de outra forma não seria possivel!

PRC - E em termos de custos? Por exemplo este espectáculo requer adereços, material, reagentes... têm uma verba atribuída pela escola?

LS - Sim, mas com algumas restrições. Não temos "carta branca"... normal- mente é atribuída uma verba limite pelo Conselho Executivo, que temos de gerir.

JCA - Mas temos também outros apoios. Por exemplo, temos o apoio de industrias químicas, que nos fornecem os reagentes necessários.

PRC - Consegue dizer-me quais as industrias que apoiaram? Acho que merecem essa divulgação.

JCA - Certamente: Cires, Dow Portugal, Ar líquido e Químigal Uniteca. Temos uma boa relação com estas empresas, inclusivamente vêm à escola ver as actividades.

PRC - E os alunos? Eu fiquei com a ideia que agora estão muito entusiasmados, mas foi fácil motivá-los no início? A adesão é espontânea? Vamos ouvir agora o professor António Almeida.

AA - É espontânea, eles colaboram nisto espontaneamente. Como já organizamos a Semana das Ciências há vários anos, eles já estão motivados a participar de um ano para o outro. Aliás o que eles querem é isto...

PRC - Quebra a rotina das aulas...

AA - Principalmente nas aulas em que a componente prática não é tão relevante. Essas são mais monótonas... e desta forma eles participam muito mais...

PRC - Pois, evidentemente, isto é uma actividade muito mais divertida do que ter aulas... mas os alunos aprendem realmente mais qualquer coisa?

AA - Aprendem. Sem dúvida que aprendem, porque uma grande parte das experiências tem muito a ver com os conteúdos das aulas. E mesmo os alunos do $12 .^{\circ}$ ano estão aqui a colaborar. E o $12 .^{\circ}$ ano é um ano muito importante para eles...

PRC - Já que falamos do $12 .^{\circ}$ ano e na importância que tem para os alunos... uma coisa que se nota neles é que a primeira ambição para prosseguimento de estudos está muito longe das ciências (Medicina, Fisioterapia,...). As ciências são pouco atraentes para os alunos?

LS - De modo nenhum, e a prova está aqui, no empenho que puseram neste trabalho, na forma como conseguiram fazer um espectáculo muito interessante.

PRC - Mas crê que este tipo de iniciativas pode mudar a visão deles em relação ao futuro, ou eles podem interessar-se por ciências mas na hora de escolher uma actividade profissional isso não conta?

LS - Quando pensam na escolha de uma actividade profissional, pensam na saída nas possibilidades que terão, e aí é sobejamente conhecido que uma licenciatura em Medicina garante mais saída que uma licenciatura em Química. 


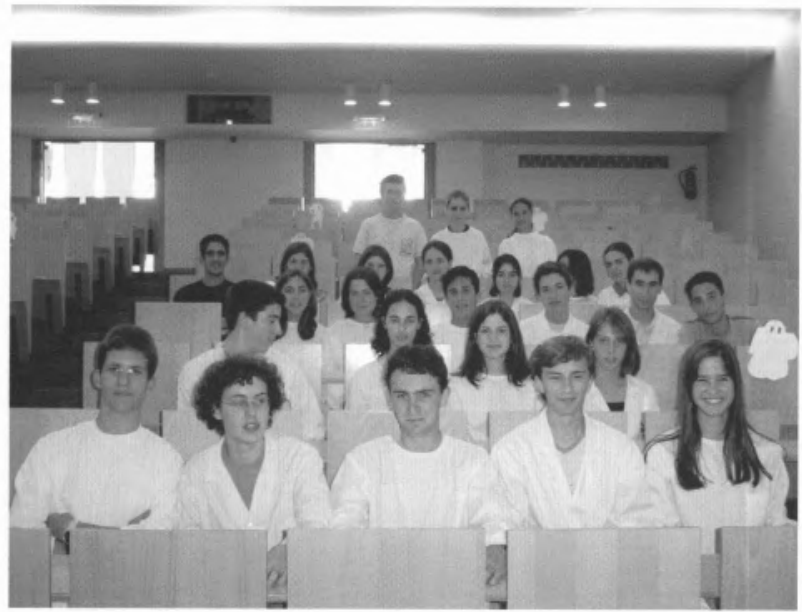

figura 30 grupo

PRC - Agora vou ouvir alguns dos alunos aqui presentes, actores e apresentadores deste espectáculo. Não vou perguntar o nome a cada um, mas incluo os nomes de toda a equipa:

Alunos participantes no espectáculo:

- Cátia Arrojado - $12 .{ }^{\circ} \mathrm{C}$

- Rosa Pereira - $12{ }^{\circ} \mathrm{C}$

- Rui Pereira - $12 .{ }^{\circ} \mathrm{C}$

- Teresa Ferreira - $12 .{ }^{\circ} \mathrm{C}$

- Tiago Corujo - $12 .{ }^{\circ} \mathrm{C}$

- Ana Carolina Trindade - $11 .^{\circ} \mathrm{B}$

- Marta Feliz Sousa - 11. ${ }^{\circ}$ B

- Sérgio Gonçalves - 11. ${ }^{\circ} \mathrm{B}$

- Fábio Matos - $11 .^{\circ} \mathrm{B}$

- Carlos Pinto - 11. ${ }^{\circ} \mathrm{D}$

- João Breda - $10 .^{\circ} \mathrm{B}$

- Daniela Guerra - $10 .^{\circ} \mathrm{B}$

- Filipa Lacerda - $10{ }^{\circ} \mathrm{B}$

- Cátia Lopes - $100^{\circ} \mathrm{B}$

- Ana Moutela - $100^{\circ} \mathrm{B}$

- Pedro Ferreira - $10 .^{\circ} \mathrm{B}$

Alunos responsáveis pela explicação posterior:

- Ana Carolina Ferreira - $10 .^{\circ} \mathrm{A}$

- Ana Luísa Domingues - 10. $\mathrm{A}$

- Ana Sofia Marques - $10 .^{\circ} \mathrm{A}$

- Andreia Gonçalves - $10{ }^{\circ} \mathrm{A}$
- Cecília Vigário - 10. A

- Eliana Almeida - $10 .{ }^{\circ} \mathrm{A}$

- Iolanda Estrela - 10. ${ }^{\circ} \mathrm{A}$

- Joana Sousa - $10 .{ }^{\circ} \mathrm{A}$

- Juliana Lamego - $10 .^{\circ} \mathrm{A}$

- Liliana Cruz - $10{ }^{\circ} \mathrm{A}$

- Mónica Costeira - $10{ }^{\circ} \mathrm{A}$

- Diana Filipa Rebelo - 10. ${ }^{\circ} \mathrm{B}$

- João Paulo Sousa - $10 .{ }^{\circ}$ B

- João Sanhudo - $100^{\circ} \mathrm{B}$

- Pedro Reis - $10 .^{\circ} \mathrm{B}$

- Rui Valente - $100^{\circ} \mathrm{B}$

PRC - Como vos foi apresentado este projecto?

Aluno \#1 - Nós tínhamos de escolher um trabalho nestas disciplinas. Depois de escolhermos, os professores disseram-nos o que tínhamos de fazer.

PRC - E a ideia agradou-vos logo, ou foram ganhando entusiasmo com o tempo?

Aluno \#2 - A partida, pareceu-nos que ia ser engraçado, mas no final foi muito mais interessante do que esperávamos, porque vimos que realmente muita coisa parece magia.

Aluno \#3 - Eu já estava ansioso pelos "Encontros com a Ciência", ou seja, a ideia agradou-me ainda antes de começar...
PRC - Foi a vossa primeira experiência deste género na Escola?

Aluno \#4 - Para alguns sim, mas já a partir do $100^{\circ}$ ano pudemos participar na Semana da Ciência (antes disso só podemos ir ver). Eu, nos anos anteriores fui à Escola ver os espectáculos que houve... mas nada parecido com isto, este ano foi uma coisa totalmente diferente.

PRC - Mas deu para aprenderem alguma coisa?

Aluno \#5 - Eu acho que o fundamental da Semana das Ciências é que, além de não ser uma aula, durante os 3 dias que lá estivemos, ao fazermos as experiências, ao estarmos a comunicar com outras pessoas, ao fazer novos amigos, aprendemos muito mais do que numa semana de aulas normais. As experiências são muito simples de fazer, mas aprende-se muito com isso.

Aluno \#6 - Nas pequenas experiências de magia que fazemos, por vezes encontramos coisas novas, que acontecem por acaso, e que nós não sabemos logo explicar. Depois de nos interrogarmos um pouco, encontramos a explicação. E também aconteceu o mesmo ao nível das relações com os outros, porque nunca imaginámos que era possível criar as amizades que criámos nos 3 dias dos Encontros com a Ciência. 


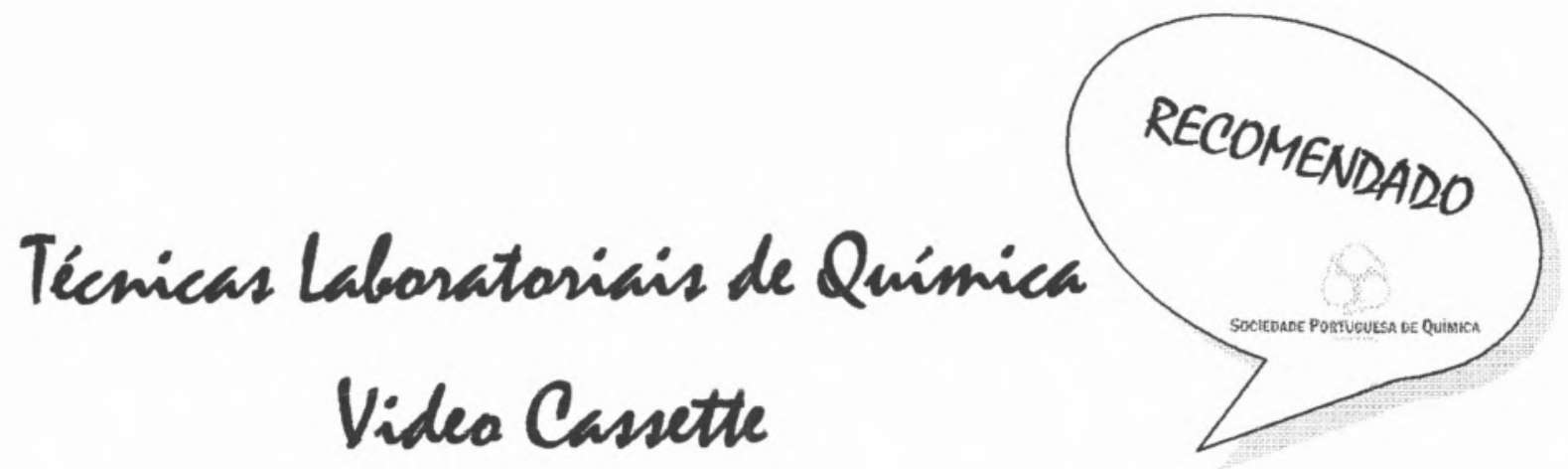

Com 7 blocos curtos e independentes, este trabalho foi concebido para apoiar as aulas de Técnicas Laboratoriais de Química destinadas a alunos do Ensino Secundário e das cadeiras introdutórias de Química do Ensino Superior. Os procedimentos apresentados são clássicos, simples e adequados para estes níveis de ensino, onde a transparência dos princípios químicos a ilustrar e a necessidade de adopção de boas práticas laboratoriais são da maior importância formativa.

\section{Índice}

Pesagem e Preparação de Soluções (11 minutos)

Operação de balanças técnicas e de precisão

Preparação de soluções rigorosas enão rigorosas

Análise Volumétrica Quantitativa (11 minutos)

Operação com pipetas e buretas

Titulações manuais

Recristalização e Fïltração (24 minutos)

Recristalização por dissolução e arrefecimento

Filtração em papel e à trompa

Filtração a quente

ExtracçãoLíquido -Líquido (7 minutos)

Operação com ampolas de decantação

Destilação (23 minutos)

Destilações simples, fraccionada,

a pressão reduzida e por arrastamento de vapor

TLC e Pontos de Fusão (9 minutos)

Cromatografia de Camada Fina

Enchimento de capilares para p.f.

Sopragem de Vidro (11 minutos)

Estirar tubos capilares

Cortar e dobrar tubos de vidro

Demonstração do fabrico e reparação de material de vidro executada por sopradores de vidro profissionais do IST.

\author{
Ficha Técnica \\ Coordenação \\ Carlos Romão \\ Hermínio Diogo \\ Texto e Locução \\ Carlos Romão \\ Execução Laboratorial \\ Hermínio Diogo \\ João Paulo Telo \\ Conceição Mesquita \\ João Ferreira \\ Carlos Nuno \\ José Luis Rodrigues \\ Filmagem e Montagem Video \\ Luís Raposo \\ Anabela Martins \\ Hermínio Costa \\ Joaquim Pinto \\ Produção \\ Núcleo de Audio Visuais \\ do IST \\ Apresentação e Duração \\ 1h 36min; Cassette VHS \\ Distribuição Exclusiva \\ Sociedade Portuguesa de Química
}

Encomendas à SPQ, Av. da República 37, 4 1050 Lisboa

Tel: 217934637 / Fax: 217952349

Preço: Instituições e não sócios $7500 \$ 00$ + IVA + portes

Sócios $6000 \$ 00+$ IVA + portes 